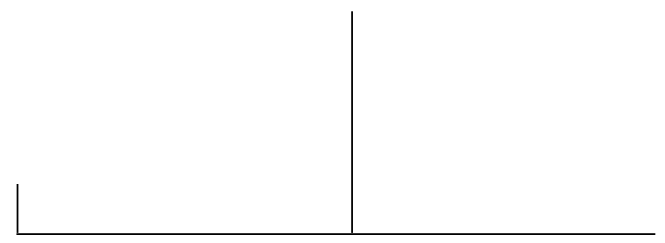

Rev. Latinoam. Psicopat. Fund., São Paulo, v. 13, n. 4, p. 558-576, dezembro 2010

\title{
Charles Darwin: um observador do desenvolvimento humano
}

\author{
Eloisa Helena Rubello Valler Celeri \\ Antonio Carvalho de Ávila Jacintho \\ Paulo Dalgalarrondo
}

Os autores traduzem, pela primeira vez para o português, o artigo de Charles Darwin “A Biographical Sketch of an Infant”, publicado no periódico Mind em julho de 1877. Utilizando anotações de observações do desenvolvimento de seus filhos, especialmente de seu filho mais velho William Erasmus (Doddy), Darwin descreve e estuda, a partir de seu enfoque naturalista, o filhote humano, narrando os primeiros indicativos comportamentais de emoções tais como raiva e medo, curiosidade e senso moral, o brincar e o prazer envolvido nesta atividade, a capacidade de imitação e os primeiros indícios daquilo que hoje conhecemos como "teoria da mente". Colocando-se questões sobre as capacidades do bebê, como eles aprendem e como se comunicam e levantando hipóteses sobre possíveis significados de certos comportamentos, questões ainda hoje fundamentais para o estudo do desenvolvimento humano, Darwin mostra-se também um pioneiro no estudo do bebê e da criança pequena, numa época na qual as capacidades dos bebês eram extremamente subestimadas e desconsideradas.

Palavras-chave: Darwin, desenvolvimento do bebê e da criança pequena 
O artigo de Charles Darwin, traduzido pela primeira vez para o português, demonstra o rigor de observação e a disciplina metódica deste grande cientista. Ele tinha como regra de ouro registrar por escrito prontamente tudo aquilo que era observado, nunca confiando na sua memória. Segundo ele, a memória costuma pregar peças na vontade de avançar o saber, retirando do campo da consciência tudo aquilo que ameaça o supostamente sabido (Darwin, 2000).

Provavelmente o investigador mais conhecido e reconhecido da história da ciência, Darwin foi um homem de seu tempo. Herdeiro de um não conformismo peculiar numa Inglaterra vitoriana, ao longo de seus 73 anos conviveu com clérigos e materialistas radicais. Após muito sofrimento íntimo e conflitos pessoais e familiares "confessou um crime" ao descrever um Universo sem Deus, fundando uma nova biologia e uma nova maneira do homem compreender a natureza e o seu destino ao reconstruir a origem e a história invisível das espécies.

Praticamente todas as áreas da biologia moderna foram inspiradas e hoje fortemente influenciadas por suas descobertas. Dentre elas, a Etologia, ou "biologia do comportamento", cujos objetos de estudo e estratégias de pesquisa foram antevistas no livro A expressão das emoções no homem e nos animais (Darwin, 2000).

Charles Robert Darwin nasceu em 12 de fevereiro de 1809, último filho de um médico (Robert) renomado e bem-sucedido e Suzannah Wedgwood, filha favorita de um rico industrial-ceramista. Recebeu este nome em homenagem ao irmão mais velho de seu pai, falecido enquanto estudava Medicina. Teve três irmãs mais velhas: Marianne, Caroline e Susan e um irmão, Erasmus. Sua mãe faleceu quando Charles estava com oito anos, passando a ser educado pelas três irmãs adolescentes.

Aos dez anos foi enviado a uma escola tradicional, rígida e entediante, onde decorar os clássicos constituía a base do currículo. 


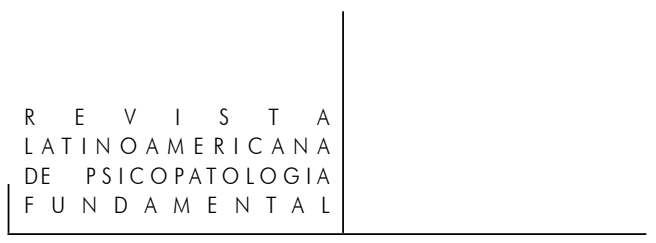

Com grande necessidade de ser aceito e reconhecido, características que se mantiveram intactas durante toda a vida, Darwin seguiu o bom comportamento de seu irmão mais velho, estudando e procurando tirar boas notas. Entretanto, o que realmente o animava eram suas coleções de pedras, rochas e besouros, as plantas da estufa de sua casa, o amor pelos cães, os experimentos com o laboratório de química que dividia com o irmão, os livros de história natural da biblioteca do pai e o exemplar de "As maravilhas do mundo", que o fazia sonhar com viagens para os trópicos e para a América do Sul. Esse período é assim descrito em sua autobiografia: “... as únicas qualidades promissoras para o meu futuro, naquela época, eram as seguintes: eu tinha preferências marcantes e diversificadas, muito empenho em tudo o que me interessava e um prazer acentuado em compreender qualquer assunto ou coisa complexos" (Darwin, 2000).

Insatisfeito com o desempenho escolar e a suposta apatia do filho e decidido a dar-lhe uma carreira, o pai retirou Charles, aos 16 anos, da escola, dois anos antes do que era esperado na época e passou a levá-lo em suas consultas. O filho registrava os sintomas e o pai fazia as prescrições. Pouco depois, enviou-o à Universidade de Edimburgo (a Atenas do Norte), como o terceiro representante da família Darwin a estudar Medicina.

Assumindo seu interesse por História Natural, Charles aprofundou-se no estudo dos hábitos e habitats de aves, larvas de moluscos e outros invertebrados marinhos, pólipos e algas simples e passou a frequentar seminários sobre geologia. Neste período foi introduzido aos textos de Lamarck.

Ao perceber o desinteresse do filho pela medicina seu pai o pressionou a escolher outra profissão. Segundo ele, faltava a Charles a disciplina exigida para o exercício da advocacia ou para a carreira militar, o que o levou a concluir que a Igreja seria o refúgio perfeito para alguém considerado "sem nenhum senso de vocação". Ainda de acordo com o pai, bastaria que Charles recebesse a educação adequada para que ele, com sua influência, conseguisse para o filho uma pequena paróquia rural, capaz de prover-lhe o sustento. Mesmo tendo dúvidas quanto a sua fé, Charles não desconsiderou a sugestão paterna, pois parecia-lhe que a vida de um pároco rural adequava-se bastante bem aos seus interesses pelo estudo das ciências naturais e a observação da natureza. Desta forma, concordou em ser enviado a Cambridge para o bacharelado em Artes e a seguir passar mais um ano frequentando palestras de teologia para se preparar para a ordenação.

Em Cambridge continuou a coletar e estudar insetos e plantas e se encantou com as descrições de Alexander Von Humboldt dos cenários tropicais das Ilhas Canárias, o que reacendeu seus sonhos infantis de excursionar pela África, América do Sul ou por ilhas tropicais. 
Ao concluir seu bacharelado e pronto para iniciar-se como pároco, candidatou-se a acompanhar o Capitão Robert FrizRoy, em uma viagem pelo litoral da América do Sul, a bordo de um navio de Sua Majestade, equipado com "modernos instrumentos para investigação naturalista". Embora Darwin não fosse o naturalista oficial da missão, apresentava as qualificações necessárias: capacidade de coletar, observar, anotar e confrontar. Assim, o jovem Charles viajou, financiado pelo pai, durante cinco anos com o Beagle. Partiu em 27 de dezembro de 1831 e retornou em 2 de outubro de 1836.

Ao voltar para a Inglaterra trouxe consigo um diário de viagem com mais de 770 páginas, cadernos de notas sobre geologia e zoologia, novas espécies, caixas e mais caixas de ossos, aves, rochas e corais. Seus catálogos listavam mais de 1.500 espécies conservadas em álcool, além de 3.907 peles, ossos e outras espécies desidratadas. $\mathrm{O}$ trabalho de estudo, análise e reflexão sobre este material duraria o resto de sua vida.

Instalado em Londres, Darwin escreveu sobre geologia e publicou seus diários de viagem, mas progressivamente suas inquietações e observações o levaram para reflexões sobre o mecanismo da evolução. A evolução e a herança dos traços físicos e dos instintos refletiram sobre a forma de transmissão dos instintos de pais para filhos e de como as características mentais se propagam de uma geração para outra. Assim, estudou a origem das expressões faciais (cujo material de observação serviu de fonte para o artigo traduzido a seguir). Nada ficava fora de sua capacidade de observação, até mesmo seus próprios sentimentos, suas impressões e devaneios.

Em julho de 1837 iniciou um caderno de notas secreto (caderno B) repleto de monólogos e reflexões. Com relutância, foi se dando conta que suas conclusões o encaminhavam para derrubar a ideia de que o homem era uma premeditação divina.

Após muito refletir e redigir uma lista de prós e contras, Charles resolveu, no ano seguinte, casar-se com uma prima-irmã, Emma Wedgwood, e com ela teve dez filhos.

Muito atento e preocupado com o funcionamento de seu corpo, concomitantemente à construção de suas teorias, um atormentado Darwin passou a sofrer de uma série de sintomas: cefaléias terríveis, dores abdominais, vômitos, flatulência, depressão, vertigens, sensação de cabeça flutuando, tremores, ataques malignos de mal-estar etc., que o fizeram mudar-se de Londres para o condado rural de Kent. Seus penosos sintomas o levaram a frequentar mais de vinte médicos e a se submeter a todo tipo de tratamentos, especialmente sessões de hidroterapia. Essa "doença misteriosa" foi objeto de livros e artigos, que ora a consideraram de etiologia orgânica (envenenamento por arsênico, doença de Chagas, alergia, porfiria etc.), ora de etiologia psíquica (hipocondria, neurose, neu- 


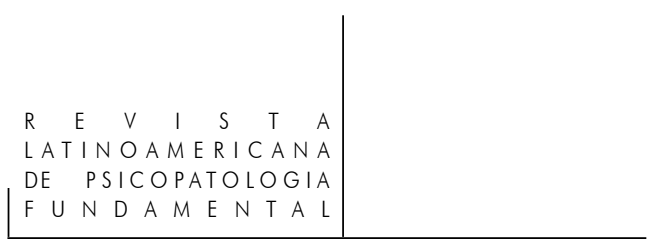

rastenia, transtorno de pânico etc.). Em 2005, Campbell et Matthews num elegante artigo de revisão crítica sustentaram uma nova hipótese diagnóstica: "Intolerância sistêmica à lactose."

Reconhecido como geólogo e naturalista, sentia que tinha uma reputação a zelar. Gozava da estima pública, era considerado pela comunidade científica internacional e temia que a publicação de suas conclusões sobre a "transmutação da vida", teoria claramente concebida em 1839, o ligassem aos ateístas, socialistas e materialistas. Descrevia suas ideias, aos amigos fiéis, como "um crime".

Em 1851, já abalado pelo falecimento do pai, viu suas crenças num universo justo e moral ruir com a morte precoce de sua muito amada filha mais velha, Annie. Seu cristianismo, que já vinha sendo colocado à prova pela suas viagens, suas observações e seus estudos, desmoronou totalmente e ele assumiu sua descrença.

Concomitantemente, ares mais liberais começavam a soprar sobre a Inglaterra vitoriana, com uma legião de novos cientistas decididos a construir uma ciência livre e independente, desvinculada dos dogmas religiosos. Influenciado pelos novos ares, Darwin decidiu começar a escrever seu "Ensaio preliminar" (14 de março de 1856), adiando a decisão sobre sua publicação.

Origins of Species veio a público em 1859, após 13 meses e dez dias de escrita intensiva (Darwin, 2000) e vinte anos de observações, reflexões, silêncio e tormentos, com pequenas sugestões sobre as origens do homem. Os 1.500 exemplares da primeira edição esgotaram-se rapidamente, novas edições foram providenciadas e em pouco tempo seu livro foi traduzido para mais de seis idiomas, ganhando o público leigo, as ruas e as salas de visitas, sendo discutido e debatido por naturalistas e intelectuais.

Já seguro do crescimento da liberalidade inglesa e constatando a aceitação de sua teoria sobre a evolução das espécies, Darwin organizou suas notas e publicou, em 1871 "Descendência do homem e a seleção sexual", um tratado sobre a origem do homem, a seleção sexual, as leis da variação e da hereditariedade. Fazia parte do projeto deste livro um pequeno ensaio que, ao ser organizado, tornou-se um outro livro, igualmente extenso A expressão das emoções no homem e nos animais, publicado em 1872. Desta forma, a obra de Darwin, após The Origins of Species irá gradualmente se concentrar sobre a origem do homem e sobre a evolução da mente, do comportamento e das emoções, tanto do homem como de outros animais próximos do humano (Ruse, 2009).

Ao atentar de forma científica para a natureza evolutiva do comportamento, Darwin chamou a atenção para o fato de que comportamentos e padrões motores são características tão confiáveis e conservadas nas espécies quanto os órgãos e músculos, devendo ser submetidos às mesmas leis de transmissão hereditária, seleção e mutação.

Rev. Latinoam. Psicopat. Fund., São Paulo, v. 13, n. 4, p. 558-576, dezembro 2010 
No artigo por nós traduzido, Darwin utiliza-se de anotações de observações de seus filhos pequenos, especialmente seu filho mais velho, William Erasmus (Doddy). Estudando o filhote humano, a partir de seu enfoque naturalista, Darwin descreve os primeiros indicativos comportamentais de emoções tais como raiva e medo, curiosidade e senso moral, o brincar e o prazer envolvido nesta atividade, a capacidade de imitação e os primeiros indícios daquilo que hoje conhecemos como teoria da mente. Colocando-se questões sobre as capacidades do bebê, como eles aprendem e como se comunicam, e levantando hipóteses sobre possíveis significados de certos comportamentos, questões ainda hoje fundamentais para o estudo do desenvolvimento humano, o artigo "Um esboço biográfico de uma criança pequena" demonstra o pioneirismo deste grande cientista no estudo do bebê e da criança pequena, numa época na qual as capacidades dos bebês eram extremamente subestimadas e desconsideradas.

Charles Darwin faleceu em 19 de abril de 1882, aparentemente de ataque cardíaco. Considerado o maior cientista inglês desde Isaac Newton, foi enterrado na célebre Abadia de Westminster.

Campbell, A. et Matthews, K. Darwin's illness revealed. Postgrad Med J, n. 81, p. 248-251, 2005.

Darwin, C. A origem do homem e a seleção sexual. São Paulo: Hemus, 1974. . Autobiografia, 1809-1882. Rio de Janeiro: Contraponto, 2000. . A expressão das emoções no homem e nos animais. São Paulo: Companhia das Letras, 2000.

Desmond, A. et Moore, J. Darwin, a vida de um evolucionista atormentado. São Paulo: Geração Editorial, 1995.

Papalia, D. E.; Olds, S.W.; Feldman, R.D. Desenvolvimento humano. Porto Alegre: Artmed, 2006.

Roudinesco, E.; Plon, M. Dicionário de psicanálise. Rio de Janeiro: Jorge Zahar, 1998.

Ruse, M. Darwin. In: Michael Ruse and Joseph Travis Evolution: The first four billion years. London: The Belknap Press of Havard University Press, 2009. 


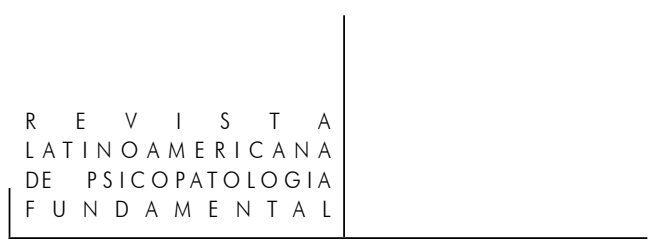

\section{Darwin, Charles - Um esboço biográfico de uma criança pequena*}

A descrição muito interessante de M. Taine sobre o desenvolvimento mental de uma criança pequena, traduzida no último número de MIND (p. 252), me fez examinar um diário a respeito de um de meus filhos, que eu guardei por 37 anos. Eu tive excelentes oportunidades para uma observação acurada e anotei simultaneamente tudo o que era observado. Meu principal objeto era a expressão, e minhas notas foram utilizadas em meu livro sobre este assunto, mas como eu atentava para alguns outros pontos, minhas observações podem possivelmente possuir algum pequeno interesse em comparação com aqueles expostos por $\mathrm{M}$. Taine e com outros que, daqui para frente, possam ser feitos. Estou seguro, a partir do que observei com meus filhos, que o período de desenvolvimento de várias habilidades diferirá consideravelmente em diferentes crianças.

Durante os primeiros sete dias de vida várias ações reflexas, por exemplo, espirrar, soluçar, bocejar, esticar-se e, obviamente, sugar e chorar são bem executadas pelos bebês. No sétimo dia eu toquei a sola nua de seu pé com um pedacinho de papel e ele retirou-o para longe, encurvando ao mesmo tempo seus dedos, como uma criança mais velha faz quando lhe fazemos cócegas. A perfeição destes movimentos reflexos mostra que a extrema imperfeição dos movimentos voluntários não se deve ao estado dos músculos ou dos centros de coordenação, mas ao aparecimento da vontade. Neste momento, apesar de muito precoce, pareceu-me claro que uma mão quente e macia aplicada sobre sua face, excitava o desejo de sugar. Isto deve ser considerado como um reflexo ou uma ação instintiva, pois é impossível acreditar que experiência e associação com o toque do seio materno possa tão cedo ocorrer.

Durante a primeira quinzena ele frequentemente movimentava-se ao ouvir qualquer som súbito e piscava os olhos. O mesmo fato foi observado com alguns de meus outros filhos, nos primeiros 15 dias de vida. Uma vez, quando ele tinha 66 dias, eu espirrei e ele movimentou-se violentamente, contraiu suas sobrancelhas, pareceu amedrontado e chorou muito, durante uma hora. Após isto, permaneceu num estado que poder-se-ia descrever como nervoso, numa pessoa mais velha, pois qualquer pequeno barulho fazia-o movimentar-se. Poucos dias após essa data, ele começou a se mexer ao ver de repente um objeto, mas após um longo tempo, sons faziam-no mexer-se e piscar os olhos muito mais

* Publicado originalmente em Mind - A Quarterly Review of Psychology and Philosophy, n. 2, 1877.

Rev. Latinoam. Psicopat. Fund., São Paulo, v. 13, n. 4, p. 558-576, dezembro 2010 
frequentemente que quando estava apenas olhando. Então com 144 dias de idade, eu balancei uma caixa de papelão com confeitos próximo a sua face e ele movimentou-se, enquanto que a mesma caixa vazia ou qualquer outro objeto balançado próximo de sua face não produzia qualquer efeito. Podemos inferir a partir destes fatos que o piscar de olhos, que manifestamente serve para protegê-los, não se adquiriu pela experiência. Apesar de sensível aos sons de maneira geral, ele não era capaz de, mesmo com 124 dias, facilmente reconhecer de onde o som partia a fim de dirigir seus olhos para a fonte.

Com respeito à visão, seus olhos se fixavam em uma vela já no nono dia e até o $45^{\circ}$ dia nada mais parecia ser capaz de mantê-los assim fixos, mas no $49^{\circ}$ sua atenção foi atraída por uma fita brilhante e colorida, como demonstrado por seus olhos fixos e pelo cessar dos movimentos de seus braços. Foi surpreendente quão vagarosamente ele adquiriu a capacidade de seguir com seus olhos um objeto que balançava rapidamente, pois ele não conseguia fazê-lo bem com sete meses e meio. Com a idade de 32 dias ele percebia o peito de sua mãe a três ou quatro polegadas de distância. ${ }^{1}$ Como era demonstrado pela protrusão de seus lábios e o fixar de seus olhos, mas eu devo duvidar se isto se associava com a visão. Ele certamente não tinha tocado o peito. Se ele era guiado pelo cheiro ou pela sensação de calor ou pela associação com a posição em que era segurado, eu não sei.

Os movimentos de seus membros e corpo foram, por um longo tempo, vagos e sem propósito e geralmente executados de uma maneira brusca, mas havia uma exceção a esta regra, especialmente esta de um período bem precoce. Bem antes dos quarenta dias, ele podia mover suas mãos até sua boca. Quando tinha 77 dias, pegava a mamadeira (com a qual ele era parcialmente alimentado) na sua mão direita, quer ele fosse segurado no braço direito ou no esquerdo da babá, e não pegaria pela mão esquerda até uma semana mais tarde, apesar de eu tentar fazer com que ele o fizesse. Assim a mão direita foi usada com uma semana de avanço em relação à esquerda. Entretanto, este menino provou, depois, ser canhoto; tendência sem dúvida herdada, pois seu avô, sua mãe e um irmão foram ou eram canhotos. Entre oitenta e noventa dias de idade, ele levava todo tipo de objetos à boca e em duas ou três semanas podia fazer isto com alguma habilidade, mas ele frequentemente primeiro tocava seu nariz com o objeto e só então o enfiava na boca. Após agarrar meu dedo e dirigi-lo para sua boca, sua própria mão impediu-o de sugá-lo, mas com 114 dias, após agir desta maneira, ele retirou sua mão de forma a poder colocar a ponta de meu dedo em sua boca. Esta ação repetiu-se muitas vezes e evidentemente não ocorreu por acaso, mas por motivos racionais.

1. 1 polegada $=2,54 \mathrm{~cm}$, ou seja, mais ou menos $8 \mathrm{~cm}$. (N. da T.) 


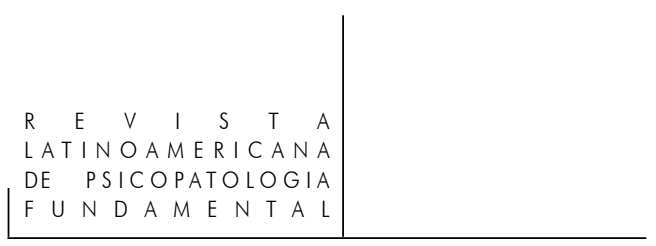

Os movimentos intencionais das mãos e braços ocorreram muito antes que os do corpo e pernas; apesar de os movimentos sem propósito destes serem desde um período bem precoce, usualmente alternados, como no ato de caminhar. Quatro meses mais tarde, ele com frequência olhava intencionalmente para suas próprias mãos e para outros objetos, colocando-os próximos dos olhos e convergindo-os de forma que ele com frequência ficava assustadoramente estrábico. Uma quinzena mais tarde (132 dias de idade) eu observei que, se um objeto era trazido tão próximo a sua face quanto eram suas mãos ele tentava agarrá-lo, mas geralmente falhava e não tentava fazer o mesmo com objetos que estavam mais distantes. Eu penso que deva haver pouca dúvida que a convergência de seus olhos dava-lhe a pista e o excitava a mover seus braços. Apesar desta criança ter começado a usar as mãos da forma indicada num período bem precoce, ele não demonstrava nenhuma habilidade especial em relação a isso, pois aos dois anos e quatro meses ele segurava lápis, canetas e outros objetos de forma muito menos precisa e eficiente, se comparado com sua irmã que tinha, então, apenas 14 meses e demonstrava uma aptidão inerente muito maior em manusear qualquer coisa.

Raiva (anger) - Era difícil decidir quão precocemente a raiva foi sentida. No oitavo dia ele franziu e enrugou a pele ao redor dos olhos antes de iniciar o choro, mas isto pode ter ocorrido devido à dor ou sofrimento e não à raiva. Quando ao redor de dez semanas foi-lhe dado leite frio, ele manteve sua testa franzida durante todo o tempo em que estava sugando, de forma que ele se parecia com uma pessoa crescida que se irrita por ser compelida a fazer algo de que não gosta. Próximo dos quatro meses e talvez muito antes, não poderia haver dúvidas, pela maneira pela qual o sangue fluía de repente para sua face e couro cabeludo, que ele facilmente estava às voltas com uma violenta paixão. Um pequeno desencadeante era suficiente, desta forma, quando, um pouco após sete meses de idade, ele gritava com fúria porque um limão escorregou para longe e ele não pôde agarrá-lo com as mãos. Aos 11 meses, se um brinquedo errado fosse dado a ele, ele o empurraria para longe e o bateria. Eu presumo que o bater era um sinal instintivo de raiva, como o abrir e fechar das mandíbulas de um jovem crocodilo assim que sai do ovo, e não que ele imaginasse poder machucar o brinquedo. Com dois anos e três meses tornou-se um grande adepto de jogar livros, galhos etc. em qualquer um que o ofendesse, e o mesmo ocorreu com alguns dos meus outros filhos. Por outro lado, eu nunca pude ver um traço de tais atitudes nas minhas filhas, o que me faz pensar que tal tendência em atirar objetos é inerente aos meninos. 
Medo (fear) - Este sentimento provavelmente é um dos mais precocemente experimentados pelos bebês, como mostrado pelo movimento desencadeado por qualquer som intenso, com apenas algumas semanas, seguido de choro. Antes que este meu filho tivesse quatro meses e meio, costumei fazer, próximo a ele, muitos barulhos estranhos e altos, que eram todos encarados como excelentes piadas, mas neste período, um dia, fiz um barulho alto como um ronco que eu nunca tinha feito antes, ele instantaneamente olhou sério e então caiu em lágrimas. Dois ou três dias após, fiz de forma inadvertida o mesmo barulho, com o mesmo resultado. Mais ou menos na mesma época (no $137^{\circ}$ dia) em que me aproximei de costas para ele, e então fiquei sem me mexer, ele ficou muito sério e surpreso e $\log$ o começaria a chorar, caso eu não tivesse me virado, então sua face instantaneamente relaxou-se num sorriso.

É bem conhecido quão intensamente as crianças mais velhas sofrem de medos vagos e indefinidos, como medo do escuro ou de passar por um canto escuro em uma grande sala etc. Posso dar como exemplo que levei a criança em questão, quando ele tinha dois anos e meio, ao Jardim Zoológico, e ele se divertiu olhando todos os animais que se pareciam com aqueles que conhecia, tais como cervos, antílopes etc. e todos os pássaros, mesmo os avestruzes, mas ficou muito alarmado com vários animais maiores nas jaulas. Frequentemente dizia, depois disto, que gostaria de voltar, mas não para ver as "feras em casas". E nós não tivemos condições de dar conta deste medo. Será que não podemos suspeitar que os medos vagos, mas muito reais, das crianças, que são bastante independentes da experiência, são os efeitos herdados de perigos reais e objeto de superstições de épocas selvagens primitivas? Isto está bem de acordo com o que conhecemos sobre transmissão de características formalmente bem desenvolvidas, que deveriam aparecer em um período bem precoce da vida e depois desaparecer.

Sensações prazerosas (pleasurable sensations) - Pode-se presumir que bebês sentem prazer enquanto sugam, e a expressão de seus olhos perdidos parece mostrar que este é o caso. Este bebê sorriu com 45 dias de vida, um segundo bebê quando estava com 46 dias, e estes sorrisos são verdadeiros indicativos de prazer, pelo brilho em seus olhos e pálpebras ligeiramente fechadas. Os sorrisos surgiam principalmente quando olhavam para a mãe e eram provavelmente de origem mental, mas então este bebê frequentemente sorria e algumas vezes depois desse período, de algum sentimento agradável interno, pois nada estava acontecendo que pudesse de alguma forma excitá-lo ou agradá-lo. Com 110 dias de idade divertia-se terrivelmente quando um avental era atirado sobre sua face e então retirado, o mesmo acontecia quando eu, de repente, cobria meu rosto e me aproximava 


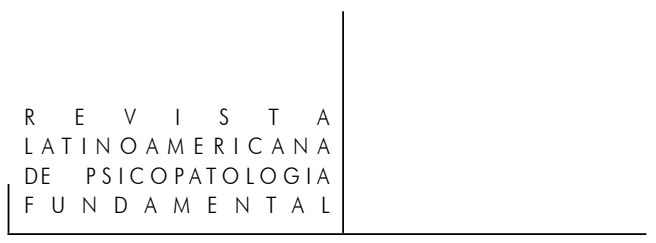

dele. ${ }^{2}$ Ele então emitia um pequeno barulho que era uma risada incipiente. Aqui, surpresa era a causa principal de sua diversão, como é o caso para uma grande parte de pessoas adultas inteligentes. Acredito que por três ou quatro semanas antes do período em que ele se divertia com uma face sendo subitamente descoberta, recebeu um pequeno aperto em seu nariz e bochechas como uma boa piada. Primeiro fiquei surpreso com o fato do humor estar sendo apreciado por um bebê um pouco acima dos três meses, mas devemos nos lembrar como pequenos filhotes de cachorro e gato começam a brincar. Com quatro meses de idade, ele demonstrou de maneira inequívoca que gostava de ouvir o piano tocar, assim este parece ser o sinal mais precoce de sentimentos estéticos, a menos que a atração por cores brilhantes, que fora exibida muito mais cedo, possa assim ser considerada.

Afeição (affection) - Esta, parece, surgiu muito cedo na vida, se julgarmos pelo seu sorriso para aqueles que cuidavam dele quando estava com mais ou menos dois meses de idade, apesar de eu não contar com nenhuma evidência clara que ele pudesse distinguir e reconhecer qualquer um, até contar com aproximadamente quatro meses. Com quase cinco meses claramente demonstrava seu desejo de ir com sua babá. Mas não demonstrava espontaneamente afeição por meio de atos explícitos até um pouco depois de um ano. Nesta idade, beijou várias vezes sua babá que havia se ausentado por um curto período de tempo. A respeito do sentimento correlacionado de simpatia, este foi claramente demonstrado aos seis meses e 11 dias pela sua face melancólica, com os cantos da boca bem depressivos, quando sua babá fingiu chorar. Ciúme foi plenamente exibido quando segurei afetuosamente uma grande boneca e quando segurei sua irmã mais nova, ele tendo, então, 15 meses e meio. Ao constatar a intensidade do ciúme em cachorros, poderíamos acreditar que provavelmente este sentimento poderia ser exibido muito mais precocemente, caso pudesse ser acessado da forma adequada.

Associação de ideias, razão etc. (association of ideas, reason) - A primeira ação em que exibiu, até onde observei, um tipo de arrazoamento prático já foi relatada, ou seja, abaixar sua mão a fim de poder colocar a ponta de meu dedo em sua boca, e isto aconteceu no $114^{\circ}$ dia. Aos quatro meses e meio ele repetidamente sorriu para minha imagem e a dele em um espelho e, sem dúvida,

2. A brincadeira de esconder o rosto e reaparecer (Peekaboo) é praticamente universal em todas as culturas, recebendo atenção de psicanalistas e psicólogos cognitivos, geralmente surgindo por volta dos seis meses e prosseguindo até o $2^{\circ}$ ano de vida. (N. da T.)

Rev. Latinoam. Psicopat. Fund., São Paulo, v. 13, n. 4, p. 558-576, dezembro 2010 
erroneamente as tomou por objetos reais; mas revelou surpresa com minha voz vindo de trás dele. Como todas as crianças, divertia-se, a partir de então, em olhar-se no espelho e, em menos de dois meses, compreendeu perfeitamente que aquilo era uma imagem, ${ }^{3}$ pois se eu fazia de forma silenciosa alguma careta esquisita, ele subitamente se voltava e olhava para mim. Ficou, entretanto, confuso aos sete meses quando, estando fora de casa, viu-me dentro, através de uma grande janela de vidro e pareceu duvidar se aquilo era ou não uma imagem. Outro de meus filhos, uma pequena menina, quando estava com exatamente um ano, não era nem de perto tão arguta e pareceu bem perplexa com a imagem de uma pessoa num espelho se aproximando dela por trás. Os primatas mais elevados, que eu testei com um pequeno espelho, comportaram-se diferentemente: eles passavam suas mãos atrás do espelho e ao fazê-lo demonstravam sua percepção, mas longe de terem prazer em se verem ficavam bravos e não queriam mais olhar.

Com cinco meses de idade, ideias associativas surgiam independentemente de qualquer instrução e tornaram-se fixas em sua mente, assim, tão logo seu chapéu e casaco eram vestidos ele ficava muito irritado se não fosse levado imediatamente para fora de casa. Com exatamente sete meses deu um grande passo, associando sua babá ao nome dela, assim, se eu a chamasse ele iria procurar por ela. Outra criança costumava balançar sua cabeça para se divertir e nós nos divertíamos e o imitávamos, dizendo "Balance sua cabeça", e quando ele tinha sete meses, algumas vezes fazia o movimento quando lhe pedíamos, sem que precisasse ser guiado. Durante os próximos quatro meses a criança observada associou muitas coisas e ações às palavras; assim, quando lhe pediam um beijo ele fazia o movimento de beijo com os lábios e permanecia parado e quieto; abanaria a cabeça e diria com uma voz de repreensão, "Ah", para a caixa de carvão ou para um pequeno espirro de água, etc. que ele havia sido ensinado a considerar como sujos. Posso acrescentar que em poucos dias, ao redor dos nove meses, ele associou seu próprio nome com sua imagem no espelho, e quando chamado

3. O ato de reconhecer-se num espelho e seu vínculo com o autorreconhecimento, a autoconsciência e a formação do eu têm sido objeto de estudo e debates, desde há muito tempo. Segundo Piaget, a consciência de si surge entre 15 e 24 meses, quando o bebê torna-se capaz de construir representações mentais de si e de outras pessoas e coisas (Papalia et al., 2006).

Henri Wallon, em 1931, descreveu uma experiência denominada "prova do espelho", momento do desenvolvimento que marca a capacidade da criança, ao ser colocada diante do espelho, de distinguir seu próprio corpo da imagem refletida. Afastando-se da visão psicológica de Wallon, Lacan descreve este processo como um momento psíquico e ontológico do ser humano, momento de constituição do ser humano a partir da identificação com o seu semelhante (Roudinesco e Plon, 1998). (N. da T.)

Rev. Latinoam. Psicopat. Fund., São Paulo, v. 13, n. 4, p. 558-576, dezembro 2010 


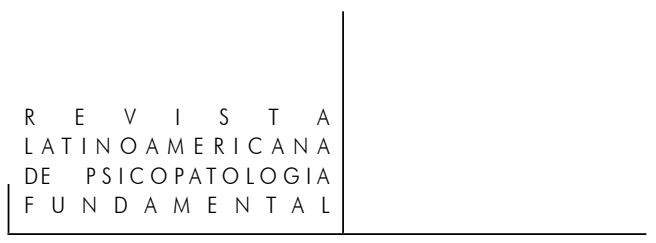

pelo nome virava-se para o espelho, mesmo estando a uma certa distância dele. Poucos dias após os nove meses aprendeu, espontaneamente, que uma mão ou outro objeto que causavam uma sombra na parede, em frente a ele, deveriam ser procurados atrás. Ao redor de um ano, bastava repetir duas ou três vezes, com intervalos, qualquer frase pequena para que ele fixasse firmemente em sua mente algumas ideias associadas. Entretanto, no bebê descrito por M. Taine (p. 254-256) a idade em que as ideias prontamente tornaram-se associadas parece ter ocorrido consideravelmente mais tarde, a menos que as situações mais precoces tivessem passado despercebidas.

A facilidade com que ideias associadas devido a instrução ou outras que surgiram espontaneamente foram adquiridas, parece para mim, de longe, a marca que distingue mais fortemente a mente de um bebê daquela do mais esperto cachorro adulto que eu vim a conhecer. Que contraste existe entre a mente de bebê com aquela do peixe (pike) descrito pelo professor Möbius ${ }^{4}$ que durante três meses inteiros atirava-se e chocava-se contra uma divisória de vidro que o separava de alguns peixes ornamentais, e então, após finalmente aprender que não poderia atacar estes pequenos peixes com impunidade, foi colocado em um aquário com eles, e assim, de uma maneira persistente e sem sentido, ele não os atacaria!

Como M. Taine ressaltou, a curiosidade se revela precocemente em crianças pequenas e é altamente importante no desenvolvimento de suas mentes, mas não fiz nenhuma observação nesta direção. Imitação, da mesma maneira, vem do brincar. Quando nosso filho tinha apenas quatro meses, pensei que ele tentava imitar sons, mas devo ter me equivocado, pois não estava totalmente convencido que ele o fizesse até os dez meses. Com 11 meses e meio ele podia prontamente imitar todo tipo de ações, tais como balançar a cabeça e dizer "Ah" para muitos objetos sujos ou cuidadosa e lentamente colocar seu dedo indicador no meio da palma de sua outra mão, ao ritmo da canção infantil "Pat it and Pat it and Mark it with T". Era divertido observar sua expressão de prazer após sua atuação bem-sucedida.

Não sei se vale a pena mencionar algo sobre a força da memória numa criança pequena. Esta, quando tinha três anos e 23 dias, ao lhe ser mostrado um retrato de seu avô, a quem não via há exatamente seis meses, instantaneamente o reconheceu e mencionou toda uma série de eventos que ocorreram enquanto o visitou e que certamente não haviam sido mencionados neste intervalo.

4. Die Bewegungen der Thiere (O movimento dos animais) etc., 1873, p. 11. 
Senso moral (Moral sense) - O primeiro sinal de um senso moral foi notado com a idade de aproximadamente 13 meses. Eu disse: "Doddy (seu apelido) não deu um beijo em seu pobre papai - Doddy desobediente". Estas palavras, sem dúvida, fizeram-no sentir-se levemente desconfortável, e por fim, quando eu retornei para minha cadeira, ele protraiu seus lábios como um sinal de que estava pronto para beijar-me e então mexeu suas mãos de uma forma raivosa até que eu voltei e recebi seu beijo.

Quase a mesma cena ocorreu em poucos dias e a reconciliação pareceu dar-lhe tanta satisfação que várias vezes mais tarde ele fingiu estar bravo e me batia e então insistia em me dar um beijo. Observamos aqui um toque de arte dramática, algo tão pronunciado nas crianças mais jovens. Por este tempo tornou-se fácil lidar com seus sentimentos e fazê-lo fazer aquilo que queríamos. Com dois anos e três meses deu seu último pedaço de gingerbread para sua irmã mais nova e depois gritou se autoaprovando: "Oh adorável Doddy, adorável Doddy". Dois meses mais tarde, tornou-se extremamente sensível ao ridículo e ficava tão desconfiado que, frequentemente, pensava que pessoas que estavam rindo e conversando juntas estavam rindo dele. Um pouco mais tarde (dois anos e sete meses e meio) eu o encontrei saindo da sala de jantar com os olhos brilhantes de forma não natural e com um jeito estranho, não natural e afetado, então entrei na sala para ver quem estava lá e descobri que ele havia pegado açúcar, o que lhe haviam dito para não fazer. Como ele nunca havia sido punido de forma alguma, sua maneira esquisita certamente se devia ao medo, e suponho que havia uma certa excitação prazerosa lutando com sua consciência. Quinze dias após, eu o encontrei vindo da mesma sala e ele estava olhando seu avental que cuidadosamente enrolara, e de novo suas maneiras eram tão estranhas que decidi ver o que havia dentro do avental, apesar dele dizer que não havia nada e repetidamente me mandar "ir embora". Então, descobri que ele estava cheio de suco, de forma que eu estava diante de uma mentira. Como esta criança foi educada exercitando seus bons sentimentos, logo tornou-se confiável, aberto e doce como qualquer um poderia desejar.

Inconsciência, timidez (Unconsciousness, Shyness) - Ninguém pode atentar para crianças muito pequenas sem se sentir tocado pela maneira desconcertante com a qual elas fixamente encaram sem piscar os olhos frente a uma nova face, uma pessoa mais velha só pode olhar desta forma para um animal ou um objeto inanimado. Isto, acredito, se deve ao fato de crianças pequenas só pensarem nelas mesmas e assim terem o mínimo de vergonha, apesar de terem, algumas vezes, medo de estranhos. Vi o primeiro sintoma de timidez em meu filho próximo aos dois anos e três meses: isto ocorreu em relação a mim mesmo, após uma ausência de dez dias. Observei que seus olhos delicadamente evitavam os meus, mas logo 


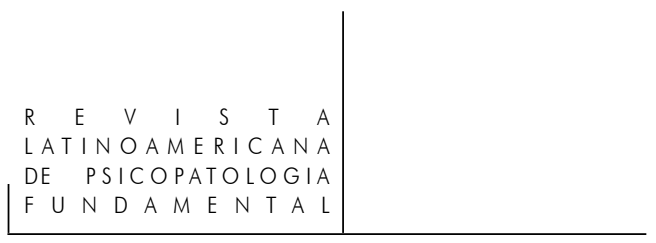

veio e sentou em meus joelhos e me beijou e qualquer traço de timidez desapareceu.

Meios de comunicação (Means of communication) - O barulho do choro ou mesmo do grito, se lágrimas não caem por um longo tempo, são claramente emitidos de forma instintiva, mas servem para mostrar que há sofrimento. Após um tempo, o som muda de acordo com a causa, seja fome ou dor. Isto foi notado quando esta criança tinha 11 semanas, e acredito que numa idade mais precoce em outra criança. Além do mais, ele rapidamente pareceu aprender a começar a chorar voluntariamente ou a franzir sua face de forma apropriada à ocasião e assim poder mostrar que queria algo. Com 46 dias ele primeiro fazia pequenos barulhos sem qualquer significado exceto dar-lhe prazer e estes rapidamente tornaram-se variados. Uma risada incipiente foi observada no $113^{\circ}$ dia, mas muito mais cedo em outro bebê. Nesta data pensava, como já assinalei, que ele começara a tentar imitar sons, como certamente fez de forma consistente num período mais tarde. Com cinco meses e meio emitiu um som articulado, "da", mas sem qualquer significado ligado a ele. Um pouco depois de um ano, usava gestos para explicar seus desejos. Para dar um pequeno exemplo: ele apanhava um pedaço de papel e dando-o para mim apontava o fogo já que ele frequentemente via e gostava de ver o papel queimar. Exatamente com um ano, deu um grande passo ao inventar uma palavra para comida, chamada mum, mas o que fez ele agir assim não foi descoberto. E a partir de então, em vez de começar a chorar quando estava com fome, ele usava esta palavra de uma maneira demonstrativa ou como um verbo, significando "dê-me comida". Esta palavra, portanto, corresponde ao ham usado pela criança de M. Taine só que numa idade posterior, 14 meses. Mas ele também usava mum como um substantivo de significado mais amplo; assim, ele chamava açúcar shu-mum e, um pouco depois aprendeu a palavra "black", e chamava xarope black-shu-mum, comida-açúcar-preto.

Eu ficava particularmente tocado com o fato de que, ao pedir comida utilizando a palavra mum, ele dava para ela (eu copiarei as palavras escritas na época) "um som marcadamente interrogativo no final". Ele também dava um som exclamativo, tal como nós empregamos quando somos surpreendidos, ao "Ah" que ele usava principalmente quando reconhecia qualquer pessoa ou sua própria imagem num espelho. Afirmei em minhas notas que o uso destas entonações parece ter surgido instintivamente, e lamento que mais observações não tenham sido feitas sobre este assunto.

Anotei que logo num período posterior, entre os 18 e 21 meses, ele modulava sua voz ao recusar-se peremptoriamente a fazer qualquer coisa com um tom de desafio, de forma a expressar, "isto eu não"; e um "hum-hum" para expressar "Sim, com certeza". M. Taine também ressalta o tom altamente 
expressivo dos sons feitos por seu bebê antes que ela aprendesse a falar. O som interrogativo que meu filho dava para a palavra mum ao pedir comida é especialmente curioso. Pois se alguém usar uma só palavra ou uma frase curta, desta forma ele descobrirá que o tom musical de sua voz crescerá consideravelmente no final. Não acho, então, que este fato afete a visão que sustentei em outro lugar: ${ }^{5}$ que antes de o homem usar a linguagem articulada, ele emitia notas numa verdadeira escala musical como faz o primata antropoide Hylobates. ${ }^{6}$

Finalmente, os desejos de um bebê são inicialmente tornados inteligíveis pelos gritos instintivos que, depois de um tempo, são modificados em parte inconscientemente e em parte, como acredito, voluntariamente, como uma maneira de comunicação - pelas expressões inconscientes peculiares, pelos gestos e de forma marcante por diferentes entonações - e, finalmente, pelas palavras naturalmente inventadas pela criança. Depois as palavras são imitadas de forma mais precisa, a partir da audição e esta capacidade é adquirida de uma forma maravilhosamente rápida.

Um bebê entende razoavelmente e, acredito, num período muito precoce, o significado ou sentimentos daqueles que dele cuidam, pela expressão de suas peculiaridades.

Não há dúvida sobre isto com respeito ao sorriso, e parece que o bebê descrito nesta biografia compreendia uma expressão de compaixão logo após os cinco meses. Aos seis meses e 11 dias ele certamente mostrava simpatia pela sua babá quando ela fingia chorar. Quando satisfeito, após realizar uma nova aquisição, tendo então quase um ano, ele evidentemente estudava as expressões daqueles que estavam ao seu redor. Isto provavelmente devia-se às diferenças de expressão, e não meramente à forma de apresentação, pois certas faces claramente o agradavam muito mais que outras, mesmo em idade bastante precoce, pouco depois de seis meses. Antes de um ano, ele compreendia entonações e gestos, assim como várias palavras e frases pequenas. Ele compreendia uma palavra, principalmente, o nome de sua babá, exatamente cinco meses antes de inventar sua primeira palavra mum, e isto é o que deve ser esperado, já que sabemos que os animais inferiores facilmente aprendem a compreender palavras faladas.

5. Ver A origem do homem e a seleção sexual, p. 105 e seguintes.

6. Gênero de primatas, representados principalmente pelos gibões do Sudeste Asiático. 


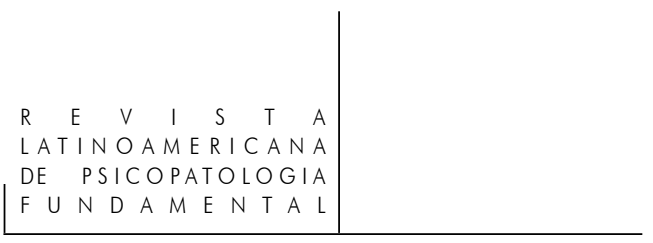

\section{Resumos}

(Charles Darwin: observer of human development)

The authors provide the first translation into Portuguese of Charles Darwin's article "A Biographical Sketch of an Infant," published in the journal Mind in July of 1877. Using notes from observations of the development of his children, especially his oldest son William Erasmus (Doddy), Darwin uses his naturalistic approach to describe and study "human puppies," providing the first behavioral indicators of emotions such as anger and fear, curiosity and moral sense. He also notes the play and pleasure involved in these activities, along with the ability to imitate and the earliest indicators of what we refer to today as "theory of the mind." Darwin raises questions about the capabilities of babies, how they learn and how they communicate and generate hypotheses about possible meanings of certain behaviors. These issues are still critical to the study of human development. This shows that he was also a pioneer in the study of babies and young children at a time when the capacity of babies was underestimated and ignored.

Key words: Darwin,development of babies and young children

(Charles Darwin: observateur du développement humain)

Les auteurs ont effectués la traduction inédite en portugais de l'article de Charles Darwin, "A Biographical Sketch of an Infant" publié dans la revue Mind en Juillet 1877. En utilisant les notes d'observations sur le développement de ses enfants, notamment de son fils aîné, William Erasmus (Doddy), Darwin étudie et décrit l'enfant humain de son point-de-vue naturaliste. Il décrit ainsi les premiers indicateurs du comportement sentimental, comme la colère et la peur, la curiosité et le sens moral, le jeu et le plaisir qu'implique cette activité, la capacité d'imiter et le début de ce que nous appelons aujourd'hui la "théorie de l'esprit". Dans cet article, Darwin pose des questions sur les capacités de l'enfant, leur façon d'apprendre et de communiquer. Il crée des hypothèses sur les possibles significations de certains comportements, questions qui sont encore aujourd'hui critiques à l'étude du développement humain et qui montrent que Darwin fut également un pionnier des études sur les bébés et les petits enfants à une époque où la capacité des bébés était gravement sous-estimée et négligée.

Mots clés: Darwin, développement des bébés et des petits enfants

(Charles Darwin: observador del desarrollo humano)

Los autores traducen por primera vez para el portugués el artículo de Charles Darwin "A Biographical Sketch of an Infant", publicado en la revista Mind, en julio de 1877. Utilizando las notas de las observaciones del desarrollo de sus hijos, especialmente la de su hijo mayor, William Erasmus (Doddy), Darwin estudia y describe,

Rev. Latinoam. Psicopat. Fund., São Paulo, v. 13, n. 4, p. 558-576, dezembro 2010 
desde su enfoque naturalista, el cachorro humano. Describe las primeras conductas indicadoras de emociones como ira y miedo, la curiosidad y el sentido moral, el juego y el placer en participar en esa actividad, la capacidad de imitar y el comienzo de lo que conocemos como "la teoría de la mente". Planteándose cuestiones sobre la capacidad del bebé, sobre como aprenden y sobre como se comunican y levantando hipótesis sobre los posibles significados de determinadas conductas; problemas que siguen siendo críticos para el estudio del desarrollo humano, mostrando que Darwin también fue un pionero en el estudio de los bebés y niño pequeño, en una época en que las capacidades de los bebés eran extremamente desconsideradas.

Palabras clave: Darwin, el desarrollo del bebé y del niño pequeño

Citação/Citation: Celeri, E.H.R.V.; Jacintho, A.C.A.; Dalgalarrondo, P. Charles Darwin: um observador do desenvolvimento humano. Revista Latinoamericana de Psicopatologia Fundamental, São Paulo, v. 13, n. 4, p. 558-576, dez. 2010.

Editor do artigo/Editor: Prof. Dr. Manoel Tosta Berlinck

Recebido/Received: 5.10.2009 / 10.5.2009 Aceito/Accepted: 8.12.2009/ 12.8.2009

Copyright: (C) 2009 Associação Universitária de Pesquisa em Psicopatologia Fundamental/ University Association for Research in Fundamental Psychopathology. Este é um artigo de livre acesso, que permite uso irrestrito, distribuição e reprodução em qualquer meio, desde que o autor e a fonte sejam citados/This is an open-access article, which permits unrestricted use, distribution, and reproduction in any medium, provided the original author and source are credited.

Financiamento/Funding: Os autores declaram não ter sido financiados ou apoiados/The authors have no support or funding to report.

Conflito de interesses/Conflict of interest: Os autores declaram que não há conflito de interesses/The authors declare that has no conflict of interest.

\section{Eloisa Helena Rubello Valler Celeri}

Psiquiatra; Profa. Dra. Departamento de Psicologia Médica e Psiquiatria da Faculdade de Ciências Médicas da Universidade Estadual de Campinas - Unicamp (Campinas, SP, Brasil); Diretora do LPPF do DPMP-FCM - Unicamp.

Rua Santo Antônio, 60, apto. 61

Fone: (19) 3521-8819

13024-440 Campinas, SP, Brasil

e-mail:evaller@fcm.unicamp.br

Rev. Latinoam. Psicopat. Fund., São Paulo, v. 13, n. 4, p. 558-576, dezembro 2010 


\section{Antônio Carvalho de Ávila JaCintho}

Psiquiatra Infantil do Departamento de Psicologia Médica e Psiquiatria da Faculdade de Ciências Médicas da Universidade Estadual de Campinas - Unicamp (Campinas, SP, Brasil).

Rua Artur Bernardes, 48

13092-130 Campinas, SP, Brasil

Fone: (19) 3251-1544

e-mail: antonioa@fcm.unicamp.br

\section{Paulo Dalgalarrondo}

Psiquiatra, professor titular Departamento de Psicologia Médica e Psiquiatria da Faculdade de Ciências Médicas da Universidade Estadual de Campinas - Unicamp (Campinas, SP, Brasil).

Rua Frei Manoel da Ressurreição, 1156

13073-021 Campinas, SP, Brasil

Fone: (19) 3251-1544

e-mail: pdalga@fcm.unicamp.br 